\title{
Soya ve Mısır Yağından Biyodizel Üretiminin Yanıt Yüzey Metodu Kullanılarak Optimizasyonu
}

\author{
Ceyla ÖZGÜR*1 \\ ${ }^{1}$ Adana Alparslan Türkeş Bilim ve Teknoloji Üniversitesi, Mühendislik Fakültesi, Enerji \\ Sistemleri Mühendisliği Bölümü, Adana
}

Geliş tarihi: 17.02.2021 Kabul tarihi: 31.03.2021

$\ddot{\mathbf{O z}}$

Bu çalışmada, soya fasulyesi ve mısır yağı karışımından biyodizel üretim prosesi için optimum parametreleri belirlemek amacıyla yanıt yüzey metoduna dayalı merkezi kompozit tasarımı (CCD) kullanılmıştır. Biyodizel üretiminin modellenmesi için dört değişkenli yanıt yüzey metoduna dayalı merkezi kompozit tasarımı uygulanmıştır. Bu nedenle, dört önemli üretimi parametresinin üç farklı seviyesinde 30 deney gerçekleştirilmiştir. Seçilen giriş parametreler, metanol/yağ oranı, reaksiyon süresi, katalizör miktarı ve reaksiyon sıcaklığıdır. En yüksek dönüşüm değeri \%94,49 ile 6,97:1 metanol/yăg oranı, 74,99 dakika reaksiyon süresinde, $\% 1,04$ katalizör miktarında, $64,99^{\circ} \mathrm{C}$ reaksiyon sıcaklığında elde edilmiştir.

Anahtar Kelimeler: Soya yağı, Mısır yağı, Biyodizel, Optimizasyon, Yüzey yanıt metodu

\section{Using Response Surface Methodology to Optimize Biodiesel Production from Soybean and Corn Oil}

\begin{abstract}
In this work, central composite design based on response surface method was used to determine optimum parameters for biodiesel production process from soybean and corn oil mixture. A central composite design (CCD) of RSM with four variables was applied to model to biodiesel production. For this reason, 30 experiments were performed for three levels of four important process parameters. The optimization parameters were methanol/oil ratio, reaction time, catalyst ratio and reaction temperature. A maximum biodiesel yield of $94.49 \%$ is accomplished at 6.97:1 methanol/oil ratio, $74.99 \mathrm{~min}$ reaction time, 1.04. $\mathrm{wt} \%$ catalyst amount and $64.99^{\circ} \mathrm{C}$ reaction temperature.
\end{abstract}

Keywords: Soybean oil, Corn oil, Biodiesel, Optimization, Response surface methodology

\footnotetext{
"Sorumlu Yazar (Corresponding author): Ceyla ÖZGÜR, cozgur@atu.edu.tr
} 


\section{GIiRiş}

Günümüzde hızla artan kentleşme ve sanayileşme, fosil yakıtların tükenmesine ve çevre kirliliğinin artmasına sebep olmaktadır [1]. Bu yüzdende düşük maliyetli hammaddelerden alternatif yakıt üretmek ve aynı zamanda çevre kirliliğini en aza indirmek için çok sayıda çalışma yapılmaktadır [2]. Bu konuda, biyodizel yenilenebilir olmas1, yüksek oranda biyolojik bozunabilirliği, yüksek parlama noktasına sahip olması ve düşük egzoz emisyonları ile büyük bir öneme sahiptir [3]. Biyodizel çoğunlukla transesterifikayson reaksiyonu ile üretilmektedir [4]. Transesterifikayon reaksiyonunda trigliseridler ve kısa zincirli alkol katalizör eşliğinde monoester üretiminde kullanılır [5]. Üretim optimizasyonu önemli ve dikkate değer bir konudur ve biyodizel veriminin arttırması ve üretim maliyetinin azalmasını sağlar [6]. Yüzey yanıt metodu komplex proseslerin geliştirilmesi, ilerletilmesi ve optimizasyonunda kullanılan ampirik bir modelleme sistemi olarak tanımlanabilir [7]. Yüzey yanıt metodolojisi birçok bilim alanında optimizasyon için tercih edilen bir uygulama metodudur [8]. Bu yöntem ile geliştirilen özel deney tasarımları kullanılarak optimizasyon için gerekli olan deney sayısı azaltılabilmekte bu da ekonomik açıdan avantaj sağlamaktadır [9]. Yanıt yüzey metodolojisi çoğunlukla biyodizel üretiminde transesterfikasyon parametrelerinin optimizasyonu için benimsenen istatistiksel bir metottur [10]. Biyodizel üretiminde proses parametrelerinin yanıt yüzey metodu yazılımı kullanılarak optimize edildiği birçok çalışma bulunmaktadır [11-14].

$\mathrm{Bu}$ çalışmanın amacı, soya-mısır yağından biyodizel üretiminde en yüksek model verimini elde etmek için çeşitli parametrelerin etkilerini ve parametreler arasındaki bu etkileşimleri ortaya koyabilmek için yanıt yüzey metodu uygulanarak sonuçların optimizasyonunu sağlamaktır.

\section{2. ÖNCEKİ ÇALIŞMALAR}

Omkaresh ve arkadaşları [15] Annona squamosa yağından biyodizel üretiminin optimizasyonu için yanıt yüzey metoduna dayalı central design tasarımı kullanmışlardır. Çalışmalarında dört bağımsız üretimi parametresinin beş farklı seviyesini kullanmışlardır. Toplamda 30 deney tasarlamışlardır ve katalizör miktarının, reaksiyon süresinin, metanol/yağ oranının ve reaksiyon sıcaklığının biyodizel verimini nasıl etkilediğini araştırmışlardır. Model sonuçlarına göre, \%94,24 Annona squamosa yağından biyodizel verimi 6,98:1 metanol/yağ oran1, 35,35 dakika reaksiyon süresi, \%1,22 katalizör miktarı ve 53,27 ${ }^{\circ} \mathrm{C}$ sicaklıkta bulunmuştur.

Yeşilyurt ve arkadaşları [16] sarı hardal tohumu yağından tek aşamalı transesterfikasyon işlemi ile biyodizel üretiminde reaksiyon parametrelerinin optimizasyonu için Central design içeren yanıt yüzey metodolojisini kullanmışlardır. Değişkenlerin biyodizel verimi üzerindeki etkilerinin incelenmesi için toplamda 30 deney tasarlamış ve gerçekleştirmişlerdir.

Kumar ve Kumar [17] portaka kabuğu yağından transesterifikasyon yöntemiyle metil ester üretiminin optimizasyonu için yanıt yüzey metodolojisini kullanmışlardır. Üretim parametreleri olarak katalizör miktarı, reaksiyon sıcaklığı, reaksiyon süresi ve metanol oranı, seçilmiştir. $\mathrm{Bu}$ çalışma sonucunda optimum \%97,22 metil ester verimi, \%0,67 katalizör miktarı, $53{ }^{\circ} \mathrm{C}$ reaksiyon sıcaklığ $1,58,16$ dakikalık bir reaksiyon süresi ve 6,27 molar oranında elde edilmiştir.

Srikanth ve arkadaşları [18] mandıra yıkanmış şüt köpüğü yağından transesterifikasyonla biyodizel üretiminin optimizasyonu için yanıt yüzey metodolojisinin Box-Behnken metodu kullanmışlardır. Metanol yağ molar oranı, $\mathrm{KOH}$ miktarıi, reaksiyon sıcaklığı ve reaksiyon süresi gibi üretim parametrelerinin biyodizel numuneleri üzerindeki etkilerini çalışmışlardır. ANOVA sonuçlarından elde edilen 2. dereceden model, modelin anlamlı ve önemli olduğunu göstermiştir. Çok küçük olan p değeri $(<0,0001)$ biyodizel verimi ve model değişkenleri arasındaki ilişkinin güçlü olduğunu göstermektedir. 
Dwivedi ve Sharma [19] dört proses değişkenini optimize ederek Pongamia yağından biyodizel verimini maksimize etmek için Box-Behnken yanıt yüzey metodolojisini kullanmışlarıdır. Metanol/yă̆ molar oranı (11,06:1) ile katalizör olarak $\mathrm{KOH}(\% 1,43 \mathrm{w} / \mathrm{w})$ kullanılarak 81,43 dakikada $56,6 \quad{ }^{\circ} \mathrm{C}$ sicaklıkta $\% 98,4$ biyodizel verimi elde etmişlerdir.

Mansourpoor ve Shariati [20] sicaklık, katalizör miktarı ve metanol/yağ molar oranı üretim parametrelerinin biyodizel verimi üzerindeki etkilerini incelemişler ve yüzey yanıt metodu kullanarak reaksiyon koşullarını optimize etmişlerdir. Metil esterlerin üretimi için maksimum verimin $48{ }^{\circ} \mathrm{C}$ sicaklıkta 6,825 molar oranda, ağırlıça katalizör konsantrasyonu, $290 \mathrm{rpm}$ karıştırma hızı ve 2 saatlik bir reaksiyon süresinde 98,181 olduğu sonucuna varmışlardır.

Kolakoti ve arkadaşları [21] çalışmalarında mahua yağından transesterifikasyon metoduyla biyodizel üretimini optimize etmek için dört farklı üretim parametresinin etkilerini araştırmışlardır. $\mathrm{Bu}$ üretim parametreleri sırasıyla, katalizör miktarı, molar oranı, reaksiyon sicaklığı ve reaksiyon süresidir. Yanıt yüzey metodu kullanılarak yapılan optimizasyon işleminde maksimum biyodizel verimi \%91,32 olarak tespit edilmiştir.

\section{MATERYAL VE METOT}

\subsection{Materyal}

Biyodizel üretiminde hammadde olarak hacimsel olarak \%50:50 soya ve mısır yağı karışımı, alkol olarak \%99,9 saflıkta metil alkol ve katalizör olarak sodyum hidroksit $(\mathrm{NaOH})$ kullanılmıştır.

\subsection{Deney Düzeneği}

Deneysel analizlerde kullanılan biyodizel soya ve mısır yağları karışımından transesterifikasyon reaksiyonu uygulanarak üretilmiştir. Biyodizel üretim prosesi Şekil 1'de gösterilmiştir.

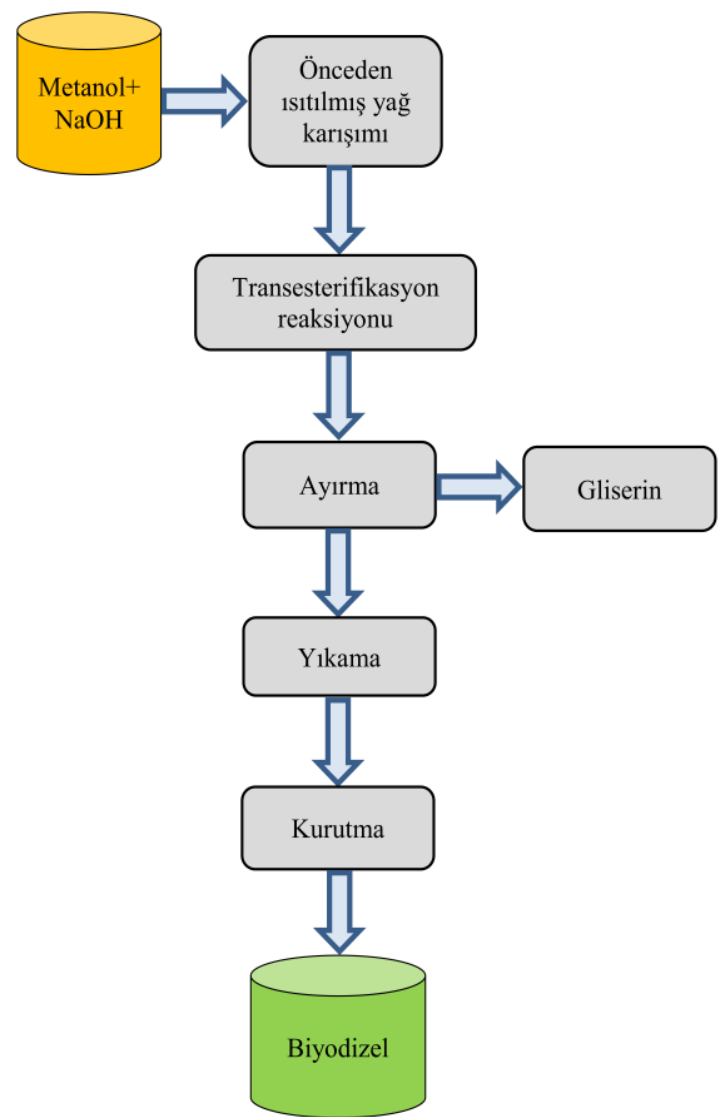

Şekil 1. Biyodizel üretim prosesi

\subsection{Yanıt Yüzey Metodu}

$\mathrm{Bu}$ çalışmada Design Expert 12 Stat-Ease, Inc., Minneapolis, MN, USA yazılımı kullanılarak deneysel değerlerin istatistiksel analizi için yanıt yüzeyi metodolojisi kullanılmıştır. Biyodizel üretim parametrelerinin optimizasyonu için Yüzey yanıt metodolojisine dayalı merkezi merkezi kompozit tasarım (CCD) kullanılmıştır. Toplamda 30 adet deney yapılmıştır. Bu tasarım 16 faktöryel nokta, 8 eksenel nokta ve 6 merkez noktası içerir. Kullanılan üretim parametreleri molar oran (A), reaksiyon süresi (B), katalizör miktarı (C) ve reaksiyon sıcaklığgidır (D). Kullanılan dört bağımsız değişken ve değerleri Çizelge 1'de verilmiştir. Yanıt yüzey metodolojisi yanıt yüzeyini tahmin etmek için 2. dereceden polinom modeli kullanılır. Bu aşağıdaki Eşitlik 1'de verildiği gibidir [22]. 


$$
Y=\beta_{0}+\sum_{i=1}^{n} \beta_{i} x_{i}+\sum_{i=1}^{n} \beta_{i i} x_{i}^{2}+\sum_{i>j}^{n} \sum_{j}^{n} \beta_{i j} x_{i} x_{j}+e
$$

Burada; Y tahmin edilen biyodizel verimi, $\mathrm{n}$ faktör sayıs1, $\beta_{0}$ sabit, $\beta_{\mathrm{i}}, \beta_{\mathrm{ii}}, \beta_{\mathrm{ij}}$ doğrusal, dörtlü ve etkileşim katsayılarıdır.

Varyans analizini değerlendirmek (ANOVA) için modelin istatistiksel bir analizi gerçekleştirilmiştir. Model uyumunun kalitesi belirleme katsayısı $\left(\mathrm{R}^{2}\right)$ kullanılarak değerlendirilmiştir ve tepki yüzey grafiği regrasyon analizinden elde edilen uygun bir kuadratik polinom denklemi kullanılarak geliştirilmiştir.

Çizelge 1. Bağımsız değişkenler ve değerleri

\begin{tabular}{|l|c|c|c|c|c|}
\hline \multicolumn{5}{|c|}{ Değerler } \\
\hline Değişkenler & -2 & -1 & 0 & 1 & 2 \\
\hline $\begin{array}{l}\text { Metanol yă̆ } \\
\text { molar oranı }\end{array}$ & 3 & 4,5 & 6 & 7,5 & 9 \\
\hline $\begin{array}{l}\text { Reaksiyon süresi } \\
(\mathrm{dk})\end{array}$ & 30 & 45 & 60 & 75 & 90 \\
\hline $\begin{array}{l}\text { Katalizör miktarı } \\
(\%)\end{array}$ & 0,3 & 0,6 & 0,9 & 1,2 & 1,5 \\
\hline $\begin{array}{l}\text { Reaksiyon } \\
\text { s1caklığ }\left({ }^{\circ} \mathrm{C}\right)\end{array}$ & 50 & 55 & 60 & 65 & 70 \\
\hline
\end{tabular}

\section{BULGULAR ve TARTIŞMA}

\subsection{Yanıt Yüzey Metodolojisi ile Optimizasyon}

Biyodizel üretiminde metanol/yağ molar orain, reaksiyon süresi, katalizör miktarı ve reaksiyon sıcaklığının etkileri merkezi kompozit tasarım (CCD) kullanılarak belirlenmiştir. Biyodizel üretiminin optimizasyonu için, merkezi kompozit tasarımında (CCD) üç seviyeli dört üretim parametresi kullanılmıştır. Çizelge 2 üretim parametrelerini ve üretim parametrelerinin seviyelerini yanıtlarla birlikte vermektedir. Çıkış parametresi olan biyodizel veriminin giriş faktörlerine göre ikinci dereceden denklemi aşağıda verildiği şekildedir (Eşitlik 2):

$$
\begin{aligned}
& Y=91,21+3,96 A-0,0296 B+3,48 C+ \\
& 1,23 D+0,4081 A B+0,7881 A C-1,03 A D+ \\
& 0,0781 B C+1,04 B D-0,4656 C D-2,75 A^{2}- \\
& 0,3703 B^{2}-3,71 C^{2}-0,4778 D^{2}
\end{aligned}
$$

Burada; Y biyodizel verimi, A metanol/yă̆ molar oranı, B reaksiyon süresi, C katalizör miktarı, D reaksiyon sıcaklığıdır.

Çizelge 2. Yanıt yüzey metodu ile belirlenen değişkenler ve yanıtlar

\begin{tabular}{|c|c|c|c|c|c|c|}
\hline $\begin{array}{c}\text { Deney } \\
\text { No }\end{array}$ & Molar oran & $\begin{array}{c}\text { Reaksiyon } \\
\text { süresi (dk) }\end{array}$ & $\begin{array}{c}\text { Katalizör } \\
\text { miktarı (\%) }\end{array}$ & $\begin{array}{c}\text { Reaksiyon } \\
\text { sicaklı̆1 }\left({ }^{\circ} \mathrm{C}\right)\end{array}$ & $\begin{array}{c}\text { Deneysel } \\
\text { biyodizel } \\
\text { verimi }(\%)\end{array}$ & $\begin{array}{c}\text { Tahmini } \\
\text { biyodizel } \\
\text { verimi }(\%)\end{array}$ \\
\hline 1 & 7,5 & 45 & 0,6 & 65 & 83 & 82,93 \\
\hline 2 & 7,5 & 45 & 1,2 & 55 & 93,5 & 92,98 \\
\hline 3 & 6,0 & 60 & 0,9 & 60 & 92,1 & 91,21 \\
\hline 4 & 6,0 & 60 & 0,9 & 70 & 90,54 & 91,76 \\
\hline 5 & 4,5 & 75 & 0,6 & 55 & 72,68 & 72,98 \\
\hline 6 & 4,5 & 75 & 1,2 & 55 & 79,56 & 79,44 \\
\hline 7 & 7,5 & 45 & 1,2 & 65 & 90,53 & 90,37 \\
\hline 8 & 6,0 & 60 & 0,9 & 60 & 91 & 91,21 \\
\hline 9 & 6,0 & 60 & 0,9 & 60 & 90,25 & 91,21 \\
\hline 10 & 7,5 & 75 & 0,6 & 55 & 83 & 82,19 \\
\hline 11 & 7,5 & 45 & 0,6 & 55 & 81,65 & 83,67 \\
\hline 12 & 6,0 & 30 & 0,9 & 60 & 90,3 & 89,79 \\
\hline 13 & 4,5 & 45 & 0,6 & 55 & 75,66 & 76,10 \\
\hline
\end{tabular}


Çizelge 2 (Devam)

\begin{tabular}{|c|c|c|c|c|c|c|}
\hline $\begin{array}{c}\text { Deney } \\
\text { No }\end{array}$ & Molar oran & $\begin{array}{c}\text { Reaksiyon } \\
\text { süresi (dk) }\end{array}$ & $\begin{array}{c}\text { Katalizör } \\
\text { miktar1 (\%) }\end{array}$ & $\begin{array}{c}\text { Reaksiyon } \\
\left.\text { sicaklığ1 ( }{ }^{\circ} \mathrm{C}\right)\end{array}$ & $\begin{array}{c}\text { Deneysel } \\
\text { biyodizel } \\
\text { verimi (\%) }\end{array}$ & $\begin{array}{c}\text { Tahmini } \\
\text { biyodizel } \\
\text { verimi }(\%)\end{array}$ \\
\hline 14 & 6,0 & 60 & 0,3 & 60 & 70,2 & 69,43 \\
\hline 15 & 6,0 & 90 & 0,9 & 60 & 89,1 & 89,67 \\
\hline 16 & 6,0 & 60 & 1,5 & 60 & 82,5 & 83,33 \\
\hline 17 & 7,5 & 75 & 1,2 & 65 & 94 & 93,37 \\
\hline 18 & 6,0 & 60 & 0,9 & 50 & 88 & 86,83 \\
\hline 19 & 4,5 & 45 & 1,2 & 65 & 83,12 & 83,74 \\
\hline 20 & 6,0 & 60 & 0,9 & 60 & 91,56 & 91,21 \\
\hline 21 & 9,0 & 60 & 0,9 & 60 & 88,9 & 88,14 \\
\hline 22 & 3,0 & 60 & 0,9 & 60 & 71,5 & 72,31 \\
\hline 23 & 4,5 & 75 & 1,2 & 65 & 87 & 85,11 \\
\hline 24 & 4,5 & 45 & 1,2 & 55 & 82,5 & 82,25 \\
\hline 25 & 4,5 & 45 & 0,6 & 65 & 80,56 & 79,46 \\
\hline 26 & 7,5 & 75 & 0,6 & 65 & 85,23 & 85,62 \\
\hline 27 & 6,0 & 60 & 0,9 & 60 & 92,1 & 91,21 \\
\hline 28 & 7,5 & 75 & 1,2 & 55 & 90,56 & 91,80 \\
\hline 29 & 6,0 & 60 & 0,9 & 60 & 90,24 & 91,21 \\
\hline 30 & 4,5 & 75 & 0,6 & 65 & 80,18 & 80,51 \\
\hline
\end{tabular}

Çizelge 3 biyodizel verimi için ANOVA tablosunu göstermektedir. Varyans analizi (ANOVA) modelin önemini bulmak için kullanılır. Her faktörün yanıt üzerindeki önemini bulmak için olasılık değeri kulanılmıştır (p-değeri) ve ayrıca her parametrenin etkileşim gücünü de gösterir. Çizelge 3'e bakıldığında p değeri 0,0001'den düşüktür ve bu da yanıt değerini tahmin etmede ve çıkan modelin uygunluğunu belirlemede yüksek derecede önemli olduğunu gösterir. Modelin F değeri 61,12 modelin önemli olduğunu kastetmektedir. 0,05'ten küçük p değerleri model terimlerinin önemli olduğunu gösterir. $\mathrm{Bu}$ durumda A, C, D, AC, AD, BD, $\mathrm{A}^{2}, \mathrm{C}^{2}$, model terimleri önemlidir. Eğer $\mathrm{f}$ değerleri yüksek ve $\mathrm{p}$ değerleri de buna karşın düşük ise modelin uygunluğu o derece iyidir. $\mathrm{Bu}$ orana Adeq Precision denir. Adeq Precision sinyal/gürültü oranını ölçer. Modelin uygunluğu için bu oranın 4 'ten büyük olması istenir. Bizim modelimizde bu oran 27,741'dir. $\mathrm{R}^{2}$ (belirleme katsayıs1) oluşturulan modelin değerlendirilmesinde kullanılır. 0-1 arasında bir değer sahip olup deneylerle uyumun iyi olup olmadığı hakkında bilgi verir. ANOVA ile regresyon denkleminin analizi, $\mathrm{R}^{2}$ değerinin 0,9828 olduğunu göstermiştir. Tahmin edilen $R^{2}$ ve ayarlanmış $R^{2}$ değerleri sirasiyla 0,9128 ve 0,9667 'dir. Tahmin edilen $R^{2}$ ile ayarlanmış $\mathrm{R}^{2}$ değerleri arasındaki fark 0,2 'den az olduğu için aralarında makul bir uyum vardır.

Tahmin edilen değerlerle gerçek değerler arasındaki mükemmel uyum Şekil 2'de gösterilmiştir. Şekilden de görüldüğü gibi tüm noktalar mükemmel uyum çizgisine çok yakındır. 
Çizelge 3. Model sonuçları (ANOVA)

\begin{tabular}{|l|c|c|c|c|c|c|}
\hline Kaynak & DF & $\begin{array}{c}\text { Kareler } \\
\text { toplam1 }\end{array}$ & $\begin{array}{c}\text { Kareler } \\
\text { ortalamas1 }\end{array}$ & F-değeri & P-değeri & \\
\hline Model & 14 & 1275,18 & 91,08 & 61,12 & $<0,0001$ & önemli \\
\hline A-Molar oran & 1 & 376,12 & 376,12 & 252,39 & $<0,0001$ & \\
\hline $\begin{array}{l}\text { B-Reaksiyon } \\
\text { süresi }\end{array}$ & 1 & 0,0210 & 0,0210 & 0,0141 & 0,9071 & \\
\hline $\begin{array}{l}\text { C-Katalizör } \\
\text { miktarı }\end{array}$ & 1 & 289,88 & 289,88 & 194,52 & $<0,0001$ & \\
\hline $\begin{array}{l}\text { D-reaksiyon } \\
\text { sicaklı̆ } 1\end{array}$ & 1 & 26,48 & 26,48 & 24,48 & 0,0002 & \\
\hline AB & 1 & 2,67 & 2,67 & 1,79 & 0,2011 & \\
\hline AC & 1 & 9,94 & 9,94 & 6,67 & 0,0208 & \\
\hline AD & 1 & 16,83 & 16,83 & 11,29 & 0,0043 & \\
\hline BC & 1 & 0,0977 & 0,0977 & 0,0655 & 0,8014 & \\
\hline BD & 1 & 17,45 & 17,45 & 11,71 & 0,0038 & \\
\hline CD & 1 & 3,47 & 3,47 & 2,33 & 0,1479 & \\
\hline$A^{2}$ & 1 & 206,72 & 206,72 & 138,72 & $<0,0001$ & \\
\hline$B^{2}$ & 1 & 3,76 & 3,76 & 2,52 & 0,1330 & \\
\hline$C^{2}$ & 1 & 377,08 & 377,08 & 253,03 & $<0,0001$ & \\
\hline$D^{2}$ & 1 & 6,26 & 6,26 & 4,20 & 0,0583 & \\
\hline Artık & 15 & 22,35 & 1,49 & & & \\
\hline Uyum eksikliği & 10 & 18,74 & 1,87 & 2,59 & 0,1523 & önemli \\
\hline Saf hata & 5 & 3,61 & 0,7227 & & & \\
\hline
\end{tabular}

$\mathrm{R}^{2}: 0,9828$, Ayarlanmış $\mathrm{R}^{2}: 0,9667$, Tahmini $\mathrm{R}^{2}: 0,9128$

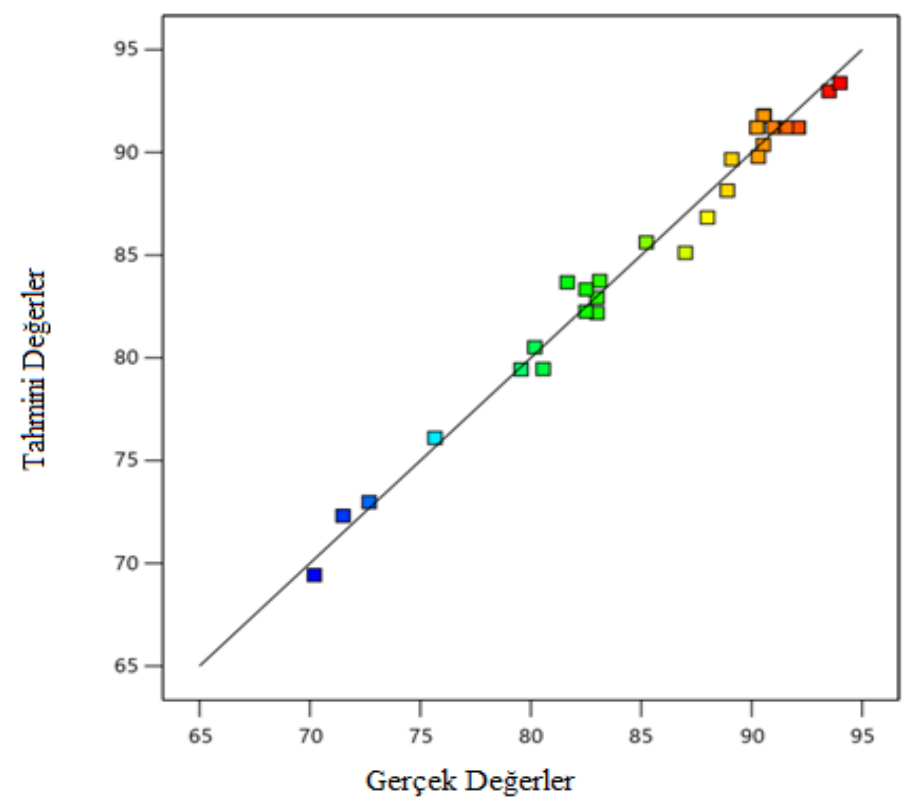

Şekil 2. Biyodizel veriminde gerçek değerlere karşı tahmin edilen değerler 


\subsection{Reaksiyon Parametrelerinin Biyodizel Verimi Üzerine Etkisi}

Transesterifikasyon prosesi sirasinda reasiyon parametrelerinin etkileşim etkileri, üç boyutlu yüzey grafikleri analiz edilmiştir. Şekil 3 katalizör miktarı ve metanol/yağ oranının biyodizel verimi üzerindeki etkisini göstermektedir. Şekil 3'de de görüldügü üzere katalizör miktarı arttıkça biyodizel veriminde de bir artış gözükmektedir, buna karşıllk reaksiyon süresi 60 dakika ve reaksiyon sicaklığ $60^{\circ} \mathrm{C}$ olarak sabit tutulduğunda molar oran arttıkça biyodizel veriminde de ufak bir artış gözlenmektedir.

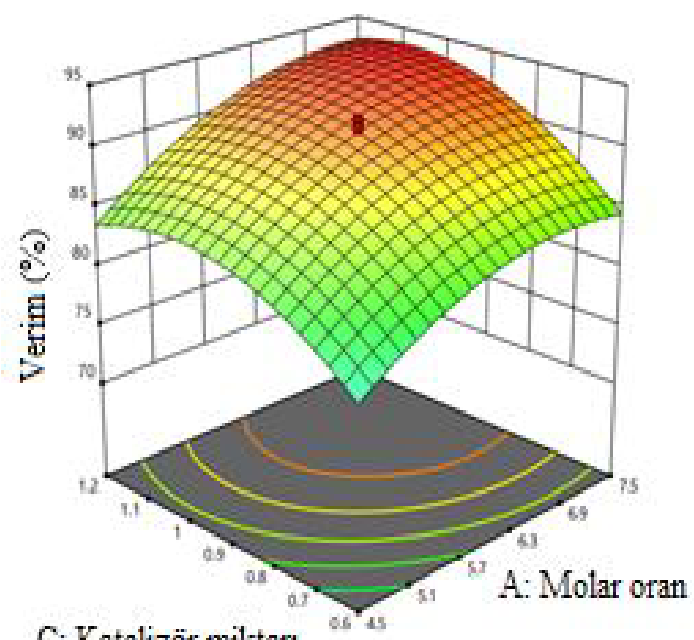

\section{C: Katalizör miktarı}

Şekil 3. Molar oran ve katalizör miktarının biyodizel verimi üzerindeki etkisinin 3 boyutlu çizimi

Şekil 4 reaksiyon sıcaklığı ve molar oranın biyodizel verimi üzerindeki karşılıklı etkileşimini göstermektedir. Şekil 4'e göre reaksiyon sicaklığı ve molar oran arttıkça biyodizel veriminde de bir artış gözlenmektedir.

Sekil 5'te reaksiyon sicaklı̆ğ ve katalizör miktarının biyodizel verimi üzerindeki önemini göstermektedir. Şekil 5'den de görüldüğü gibi reaksiyon sicaklı̆ğının artması ile reaksiyon veriminde önemli bir artış görünmemesine rağmen katalizör miktarı arttıkça biyodizel veriminde ciddi bir artış gözlenmektedir.

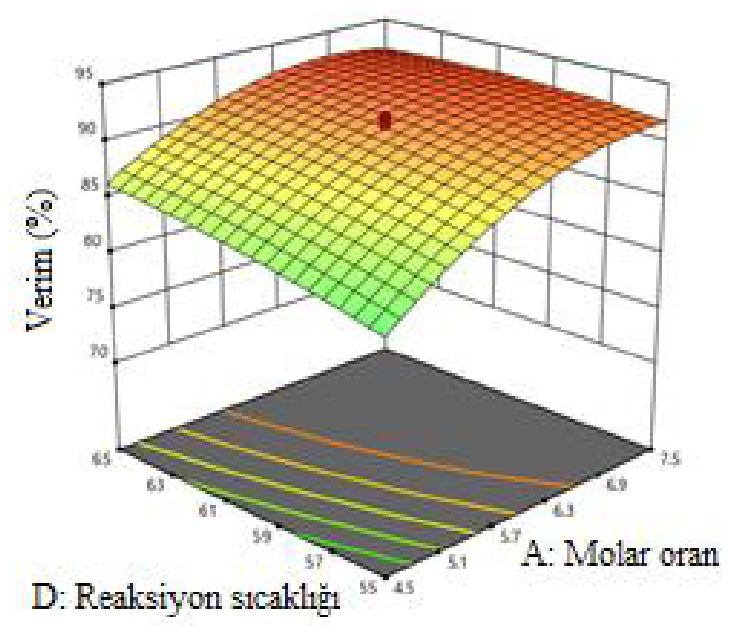

Şekil 4. Molar oran ve reaksiyon sıcaklığının biyodizel verimi üzerindeki etkisinin 3 boyutlu çizimi

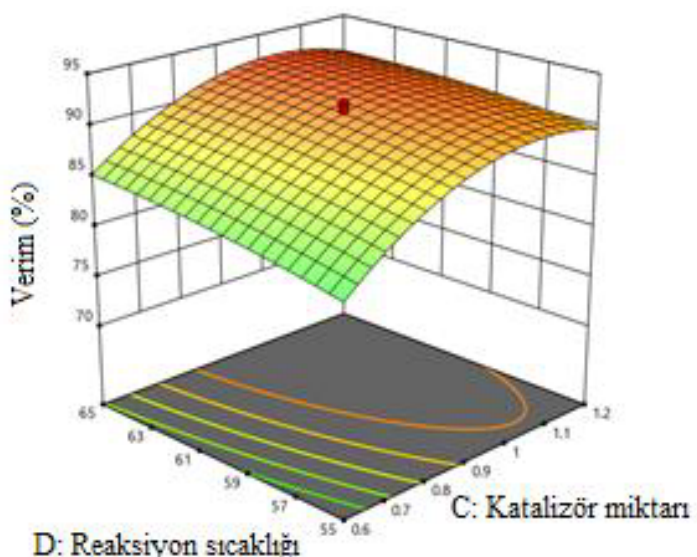

Şekil 5. Katalizör miktarı ve reaksiyon sıcaklığının biyodizel verimi üzerindeki etkisinin 3 boyutlu çizimi

\section{3. Üretim Optimizasyon Tekniği}

Yanıt yüzey metodundan elde edilen regresyon polinom denklemi her bir üretim parametresinin optimum seviyesinde maksimum yanitı hesaplamak için kullanılmıştır. Biyodizel üretim parametrelerinin optimum değerleri Şekil 6'da gösterilmektedir. Optimum değiş̧en değerleri: 6,97:1 metanol/yağ oran1, 74,99 dakika reaksiyon süresi, \%1,04 katalizör miktarı, $64,99^{\circ} \mathrm{C}$ reaksiyon sıcaklı̆̆ıdır. Bu optimum değerlerde tahmin edilen 
biyodizel verimi $\% 94,49$ 'dur. Optimum değerler temel alınarak yapılan deneysel çalışmada elde edilen biyodizel verimi \%94,0’tür. Elde edilen
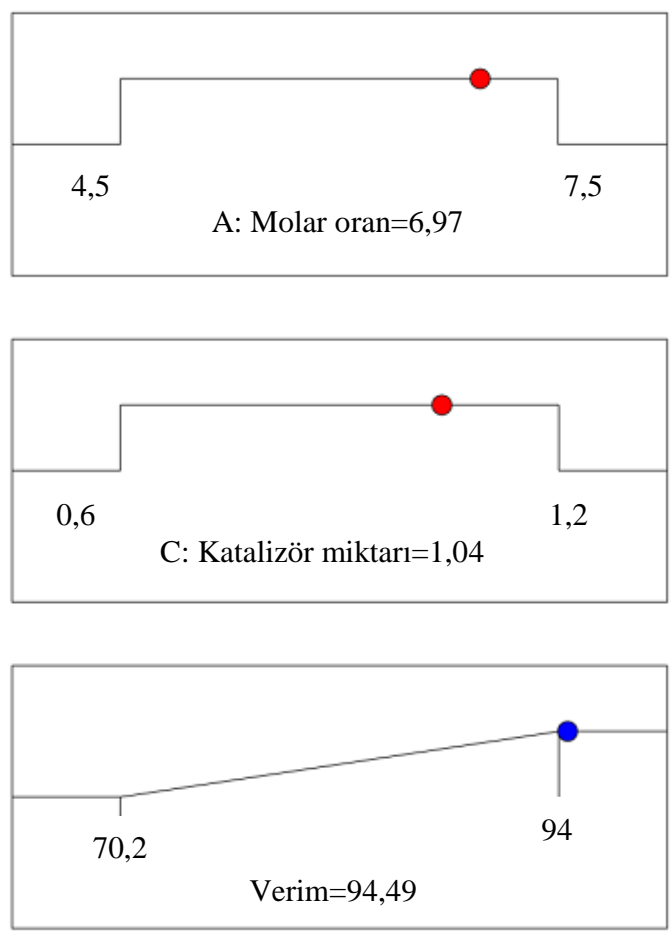

Şekil 6. Üretim parametrelerinin optimal seviyeleri

\section{SONUÇLAR}

Soya-mısır yağı karışımından biyodizel üretiminde transesterifikasyon yöntemi kullanılmıştır. Metil ester verimini maksimize etmek için reaksiyon parametreleri yanıt yüzey metodolojisine dayalı merkezi kompozit tasarımı (CCD) kullanılarak optimize edildi. Deneysel sonuçların analizine dayanarak, aşağıdaki sonuçlar elde edilmiştir:

Optimum reaksiyon parametreleri 6,97:1 metanol/yağ oranı, 74,99 dakika reaksiyon süresi, $\% 1,04$ katalizör miktarı, 64,99 ${ }^{\circ} \mathrm{C}$ reaksiyon sicaklığıdır. \%94,49'luk optimum biyodizel verimi optimal reaksiyon koşullarında elde edilmiştir.

Biyodizel modeli için $\mathrm{R}^{2}$ belirleme katsayısı 0.9828 olarak bulunmuştur ki bu da modelin doğruluğunun göstergesidir. sonuçlar karşılaştırıldığında deneysel sonuç ile yanıt yüzey metodundan elde edilen sonuç arasında $\% 0,52$ 'lik bir hata olduğu görülmektedir.
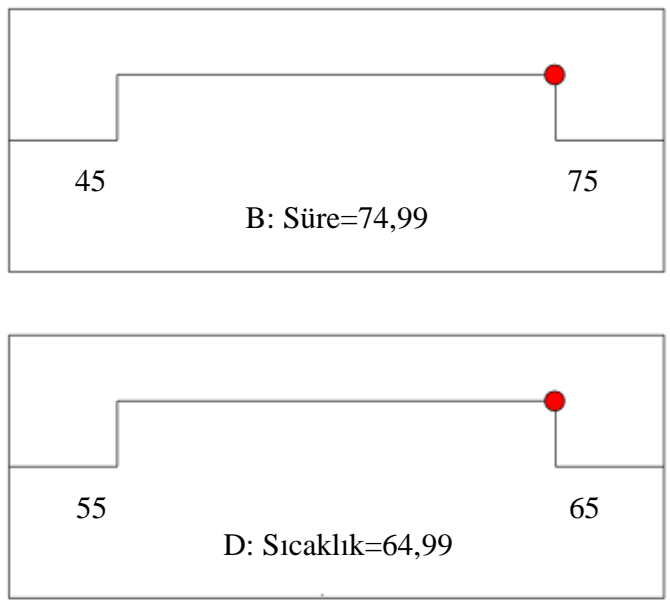

Elde edilen sonuçlar, tahmin edilen biyodizel verimi ile \%94,49, test edilen verim \%94,0 arasında çok iyi bir uyum olduğunu göstermektedir.

$\mathrm{Bu}$ da gösteriyor ki yanıt yüzey metodu biyodizel üretim parametrelerinin optimizasyonuna etkili bir şekilde uygulanabilir.

\section{KAYNAKLAR}

1. Adam, I.K., Aziz, A.R.A., Yusup, S., Heikal, M., Hagos, F., 2016. Optimization of Performance and Emissions of a Diesel Engine Fuelled with Rubber Seed-Palm Biodiesel Blends Using Response Surface Method, Asian Journal of Applied Sciences, 4(2), 401-421.

2. Bharadwaj, A.V.S.L., Sai, Niju, S., Begum, K., Meera, M., Anantharaman, N., 2019. 
Optimization and Modeling of Biodiesel Production Using Fluorite as a Heterogeneous Catalyst, Energy Sources, Part A: Recovery, Utilization, and Environmental Effects, 41(15), 1862-1878.

3. Shah, M., Ali, S., Tariq, M., Khalid, N., Ahmad, F., Khan, M.A., 2014. Catalytic Conversion of Jojoba Oil into Biodiesel by Organotin Catalysts, Spectroscopic and Chromatographic Characterization, Fuel, 118, 392-397.

4. Samuel, O.D., Okwu, M.O., 2019. Comparison of Response Surface Methodology (RSM) and Artificial Neural Network (ANN) in Modelling of Waste Coconut Oil Ethyl Esters Production, Energy Sources, Part A: Recovery, Utilization, and Environmental Effects, 41(9), 1049-1061.

5. Kumar, S., 2020. Comparison of Linear Regression and Artificial Neural Network Technique for Prediction of a Soybean Biodiesel Yield. Energy Sources Part A: Recovery, Utilization, and Environmental Effects, 42(12), 1425-1435.

6. Anbessa, T.T., Karthikeyan, S., 2019. Optimization and Mathematical Modeling of Biodiesel Production using Homogenous Catalyst from Waste Cooking Oil. International Journal of Engineering and Advanced Technology, 9(1), 1733-1739.

7. Betiku, E., Omilakin, O.R., Ajala, S.O., Okeleye, A.A., Taiwo, A.E., Solomon, B.O., 2014. Mathematical Modeling and Process Parameters Optimization Studies by Artificial Neural Network and Response Surface Methodology: A Case of Non-edible Neem (Azadirachta indica) Seed Oil Biodiesel Synthesis, Energy, 72, 266-273.

8. Uslu, S., 2019. Atık Lastik Piroliz Yağı-Dizel Karışımları ile Çalışan Bir Dizel Motorda Emisyon ve Performansın Eşzamanlı Tahminine Yönelik Bir Yanıt Yüzey Metodolojisinin Geliştirilmesi. Düzce Üniversitesi Bilim ve Teknoloji Dergisi 7, 1261-1278.

9. Demirkol, S., 2005. Soya Yağının Enzimatik Alkolizi ile Yağ Asidi Metil Esterleri Üretiminin Optimizasyonu. Yüksek Lisans Tezi, İstanbul Teknik Üniversitesi, Fen Bilimleri Enstitüsü, 91.
10. Kumar, S., Jain, S., Kumar, H., 2017. Process Parameter Assessment of Biodiesel Production from a Jatropha-algae Oil Blend by Response Surface Methodology and Artificial Neural Network. Energy Sources, Part A: Recovery, Utilization, and Environmental Effects, 39(21), 19-25.

11. Tshizanga, N., Aransiola, E.F., Oyekola, O., 2017. Optimisation of Biodiesel Production from Waste Vegetable Oil and Eggshell Ash, South African Journal of Chemical Engineering, 23, 145-156.

12. Hamze, H., Akia, M., Yazdani, F., 2015. Optimization of Biodiesel Production from the Waste Cooking Oil Using Response Surface Methodology, Process Safety and Enviromental Protection, 94, 1-10.

13. Danish, M., Kale, P., Ahmad, T., Ayoub, M., Geremew, B., Adeloju, S., 2020. Conversion of Flaxseed Oil into Biodiesel Using $\mathrm{KOH}$ Catalyst: Optimization and Characterization Dataset, Data in Brief, 29, 105225.

14. Jahirul, M.I., Koh, W., Brown, R.J., Senadeera, W., O’Hara, I., Moghaddam, L., 2014. Biodiesel Production from Non-Edible Beauty Leaf (Calophyllum inophyllum) Oil: Process Optimization Using Response Surface Methodology (RSM). Energies 7, 5317-5331.

15. Omkaresh, B.R., Suresh, R., Yatish, K.V., 2017. Optimization of Annona Squamosa Oil Biodiesel Production by Using Response Surface Methodology, Biofuels, 8(3), 377-382.

16. Yeşilyurt, M.K., Arslan, M., Eryılmaz, T., 2019. Application of Response Surface Methodology for the Optimization of Biodiesel Production from Yellow Mustard (Sinapis alba L.) Seed Oil, International Journal of Green Energy, 16(1), 60-71.

17. Kumar, P., Kumar, N., 2021. Process Optimization for Production of Biodiesel from Orange Peel Oil Using Response Surface Methodology. Energy Sources Part A: Recovery, Utilization and Enviromental Effects, 43(6), 727-737.

18. Srikanth, H.V., Venkatesh, J., Godiganur, S., 2021. Box-behnken Response Surface Methodology for Optimization of Process Parameters for Dairy Washed Milk Scum Biodiesel Production. Bifuels, 12(1), 113-123. 
19. Dwivedi, G., Sharma, M.P., 2015. Application of Box-behnken Design in Optimization of Biodiesel Yield from Pongamia Oil and its Stability Analysis. Fuel, 145, 256-262.

20. Mansourpoor, M., Shariati, A., 2012. Optimization of Biodiesel Production from Sunflower Oil Using Response Surface Methodology. J Chem Eng Process Technol, 3(4), 141.

21. Kolakoti, A., Jha, P., Mosa, P.R., Mahapatro, M., Kotaru, T.G., 2020. Optimization and Modelling of Mahua Oil Biodiesel Using RSM and Genetic Algorithm Techniques. Mathematical Models in Enginnering, 6(2), 134-146.

22. Elkelawy, M., Bastawissi, H.A-E., Esmaeil, K. K., Radwan, A.M., Panchal, H., Sadasivuni, K. K., Suresh, M., Israr, M., 2020. Maximization of Biodiesel Production from Sunflower and Soybean Oils and Prediction of Diesel Engine Performance and Emission Characteristics Through Response Surface Methodology, Fuel, 266, 117072. 